\title{
De economía popular a economía popular y solidaria en Quito: el caso de los indígenas urbanos inmigrantes del barrio San Roque
}

\author{
Oscar Jaramillo Carvajal \\ Víctor Jácome Calvache
}

RESUMEN: Este artículo analiza -desde el enfoque sustantivista de lo económico y las reflexiones teóricas alrededor de la economía popular y economía popular y solidaria- el proceso de transición de una economía popular a formas económicas solidarias, impulsado por los indígenas urbanos inmigrantes de la ciudad de Quito, Ecuador, expresamente los que habitan en el barrio San Roque. La investigación evidenció que el proceso mencionado tuvo su génesis en la década de 1970 y tomó fuerza en la primera década del siglo XXI. Durante este periodo los indígenas conformaron emprendimientos individuales o familiares y, posteriormente, constituyeron cooperativas financieras, de vivienda y cajas de ahorro y crédito, como producto de la mediación de dos elementos: (1) las relaciones solidarias que los indígenas desarrollaban en sus comunidades de origen y que, transformadas, las reprodujeron en la ciudad; y (2) la necesidad de superar las dificultades ocasionadas por la exclusión del sistema financiero, falta de trabajo y de vivienda. Con este trabajo pretendemos contribuir a los estudios de la economía popular y solidaria en ámbitos urbanos, ya que experiencias como la de los indígenas urbanos inmigrantes de San Roque han sido subsumidas por la perspectiva de la economía popular. La información que se presenta fue obtenida mediante la aplicación de la metodología cualitativa, en especial, el método etnográfico.

PALABRAS CLAVE: Economía social, organizaciones, inmigrantes, cooperativas, economía en transición, antropología económica, reciprocidad.

CLAVES ECONLIT: A13, D23, J61, P13, P2, Z1.

Cómo citar este artículo / How to cite this article: JARAMILLO, O. \& JÁCOME, V. (2019): "De economía popu-

lar a economía popular y solidaria en Quito: el caso de los indígenas urbanos inmigrantes del barrio San

Roque", CIRIEC-España, Revista de Economía Pública, Social y Cooperativa, 96, 155-187. DOI: 10.7203/CIRIEC-E.96.12148.

Correspondencia: Oscar Jaramillo Carvajal, e-mail: oscarvladimir9@hotmail.com, y Víctor Jácome Calvache, vicj2c@ hotmail.com, Instituto de Altos Estudios Nacionales - La Universidad de Postgrado del Estado, QuitoEcuador. 


\section{EXPANDED ABSTRACT}

\section{From a Popular Economy to a Popular and Solidarity Economy in Quito: A Case of Indigenous Urban Immigrants in the San Roque Neighborhood}

\section{Objective}

The purpose of this paper is to analyze the process of transition from a popular economy to a solidarity economy in the City of Quito, Ecuador. This process was fostered by indigenous urban immigrants, specifically those living in the city's San Roque Neighborhood.

\section{Participants and context}

During the second half of the twentieth century, Latin American countries saw a wave of internal migration, which was characterized by the arrival of rural, peasant indigenous to large cities. Ecuador was no exception. Its two largest cities, Quito and Guayaquil, were the most popular points of arrival. In Quito, new residents met up in specific neighborhoods, particularly those located in the southern part of the city and in the Historic Old Town, where the both cost of land and rent were much lower. This population includes a very particular group: the indigenous, who quickly began to reproduce their traditional economic, cultural, political, and social practices in symbiosis with the urban way of life, becoming known as urbanite indigenous. This phenomenon was found throughout Latin America.

Quito received settlers from the provinces of Chimborazo, Cotopaxi, Tungurahua, and Imbabura, and one of the neighborhoods where they arrived was San Roque. Here, they carried out popular economic activities that helped them to obtain the resources they needed to survive in a new context. For example, they worked as bricklayers, baggers and loaders in marketplaces, restaurants, grocery stores, tailors, etc. They went on to create cooperatives, cash pools or community savings banks, and associations that helped them to guarantee the dignified living conditions they needed to ensure more than merely their survival, both for those who were already living in the city, as well as for newcomers from rural areas.

\section{Methodology}

This all led to the proposal of a methodological framework to better understand and interpret this transition from a popular economy to the popular and solidarity economy that we see today. We begin based on the premise that in order to research economic experiences that are a far cry from what the prevailing capitalist, business-centered economic system has established, we must first look at method- 


\section{DE ECONOMÍA POPULAR A ECONOMÍA POPULAR Y SOLIDARIA EN QUITO: EL CASO DE LOS INDÍGENAS URBANOS INMIGRANTES DEL BARRIO SAN ROQUE}

ologies are rarely used in economic issues. Then we can continue on to better understand the players involved, their subjectivities and intersubjectivities. Having established this framework, we undertook a qualitative methodological strategy, specifically, ethnography and case studies.

The ethnography side involved four steps: 1) Observation and open participation in the daily life of the urbanite indigenous living in the San Roque Neighborhood in 2016 and during the first quarter of 2017. 2) Visits to several small businesses helped us to gain a better understanding of the neighborhood's social and economic organizations. In this step of the process, we had the support of researchers from the City Institute of the Municipality of Quito, who put us in contact with the San Roque neighborhood leaders. 3) Holding in-depth interviews and working with focus groups. We verbally requested permission to record interviews and take photographs. 4) Understanding and theoretical interpretation of the cases through the substantivist approach of the economy and the theoretical reflections of the popular economy and popular and solidarity economy. We also used an operative concept of indigenous urban immigrants.

We chose three organizations for our case studies: a savings and loan cooperative, housing cooperative, and a savings bank. In applying this method, we considered the following elements: information and a diagnosis of the organization, activities, operations, and the presence of solidarity. We verified that the players in the popular economy moved to create an organization within the popular and solidarity economy, and saw how they implemented the principles of cooperatives, the popular and solidarity economy, and the concept of Good Living [a concept expressed in the native Kichwa language]. To collect information, we put together a matrix that covered the abovementioned points, including information resulting from ethnographic work that allowed us to find that the analyzed cases fulfill the parameters needed to be considered practices specific to the popular and solidarity economy.

\section{Results}

The information obtained from our research showed that urbanite indigenous immigrants in the San Roque Neighborhood created economic strategies to overcome their problems and satisfy their needs without turning to assistance from the state or the private sector. These strategies can be divided up into two major groups. The first was developed first back in 1970 and can be identified as one of a popular economy, in which, either individually or as families, they created grocery shops, small restaurants, bakeries, and a wide range of services in marketplaces. The second group can be called a popular and solidarity economy; it gained steam near the end of the 20th century and in the first decade of the 21 st century. This is characterized by the principles of solidarity, participatory democracy, transparency, reciprocity, mutual assistance, etc., and is made up of cooperatives, associations, and cash pools. We found that in San Roque, a process took hold that transformed the popular economy into one reflecting more of a solidarity economy, without eliminating the first. However, these new economic strategies are unable to guarantee, in an associative sense of the word, material aspects such as access to jobs, savings, credit, housing, healthcare. Also, being something quite new, symbolic aspects that 
are the result of its community relationships that were initially developed in their native regions and are now being reproduced in a new territory: the city. These aspects include trust, community governance, collective work, and mutual assistance.

\section{Limitations of the research}

It is important to point out that minimal quantitative information is provided about the organizations we analyzed, and there is a reason for this. Our access was limited by actions taken by the Superintendent of the Popular and Solidarity Economy, in which a savings and loan cooperative was intervened by the government, leading to its closure. This caused the key players to have a certain level of distrust, and as a result, they did not allow us access to their minutes, records of deposits, loans, assets, etc., which were necessary for us to better understand aspects related to the administration, financial inclusion, or origin of the organizations.

\section{Practical conclusions and original value}

These results allowed us to reach the following practical conclusions: a) It is important not to homogenize indigenous groups, but rather differentiate them depending on their contexts in order to give visibility to a population group that lives in cities using economic practices that are different from the capitalist, business-based economies or public economies; $b$ ) The economic practices of urbanite immigrants in Quito should not be limited to the popular economy, as they have been reflected in several studies, since there is a more organized level of action, which is that of the popular and solidarity economy; c) We have included considerable information about the popular economy and the popular and solidarity economy of urbanite indigenous immigrants in the San Roque neighborhood in the case study, since local public policymakers need to understand the particularities of these groups in order to create policies that respond to their stakeholders' needs. This can also be of great use in proposing public policies that contribute to moving from merely a popular economy to more of a solidarity economy.

The importance that this article is derived from its presentation of a population group that is found not only in Quito, but throughout Latin America. Thus, the work done here can contribute to comprehending the economies of that entire population. It is also important to point out that our focus was different from that of other work done on urbanite indigenous in the San Roque neighborhood, which have limited their analysis to the popular economy, effectively making other aspects of the economy, governed by solidarity, mutual assistance, and community governance, among others, absolutely invisible. To close, as mentioned above, this knowledge is indispensable to all levels of government to ensure that the state is able to create public policies that ensure it fulfills the 2008 constitutional mandate, which declares that Ecuador has a social and solidarity economy, and a subsystem of popular and solidarity economy.

KEYWORDS: Social economics, organizations, immigrant, cooperatives, transition economies, economic anthropology, reciprocity. 


\section{DE ECONOMÍA POPULAR A ECONOMÍA POPULAR Y SOLIDARIA EN QUITO: EL CASO DE LOS INDÍGENAS URBANOS INMIGRANTES DEL BARRIO SAN ROQUE}

\section{Introducción*}

América Latina experimentó un incremento de la migración interna, desde el campo a la ciudad y de las ciudades pequeñas a las capitales, durante el siglo XX. De manera más específica, en la década de 1970 la ola migratoria estuvo constituida más por indígenas rurales y campesinos (Razeto, 1993). Pronto, en los principales focos de atracción, aparecieron barrios habitados por inmigrantes que empezaron a reproducir sus prácticas económicas, culturales, políticas y sociales en simbiosis con los modos de vida urbana. Refiriéndonos concretamente a los indígenas, se resistieron, en muchos casos, a no abandonar sus identidades étnicas, pasando de ser rurales a ser reconocidos como indígenas urbanos. Este fenómeno se presentó a lo largo de Latinoamérica y ha sido motivo de estudio desde diferentes enfoques: históricos, sociológicos, antropológicos, entre otros. Así podemos señalar los trabajos de Rossana Barragán (2009) para el caso boliviano, Eduardo Kingman (2006) en Quito, Marisol de la Cadena (2004) en Perú, Manuela Camus (2002) en Guatemala, entre otros, que, en términos generales, visibilizan las estrategias que esta población ha ido creando a fin de sobrevivir y subsistir en la urbe.

Concentrando el tema en la ciudad de Quito, se evidencia la presencia de dos grupos de indígenas urbanos: aquellos que vivieron en la periferia de la ciudad desde tiempos prehispánicos y que fueron incorporados a la mancha urbana como consecuencia de la expansión urbana acelerada a partir de la década de 1940 (Jácome, 2011); el segundo grupo proviene del proceso migratorio anteriormente descrito que, para el caso de Quito, emana de las provincias de Chimborazo, Cotopaxi, Tungurahua e Imbabura, cuya residencia la establecieron en el sur de la urbe y el Centro Histórico, entre estos el barrio San Roque, el cual históricamente se ha caracterizado por acoger indígenas inmigrantes y mantener una economía popular (Minchom, 2007).

Para efectos de este trabajo se considera al segundo grupo, a quienes hemos denominado como indígenas urbanos inmigrantes. Esencialmente aquellos que se ubicaron en el barrio San Roque, para de esta forma mostrar teorética y empíricamente que estos grupos al arribar a la urbe quiteña en la década de 1970 impulsaron, de manera individual y familiar, prácticas económicas populares que entrañaban lógicas solidarias que encausaron una transición a prácticas económicas populares y solidarias, en especial, cooperativas y asociaciones y así satisfacer sus necesidades materiales e inmateriales. En general, este artículo busca responder la pregunta: ¿De qué manera se desarrollaron los procesos de transición de una economía popular a una economía popular y solidaria, específicamente cooperativa y asociativa, motivados por indígenas urbanos inmigrantes establecidos en el barrio San Roque de Quito?

* Los autores agradecemos a la doctora Susana Hintze, docente e investigadora de la Universidad Nacional de General Sarmiento, Argentina, por las sugerencias realizadas a la versión preliminar de este artículo. 
Es importante señalar que San Roque ha sido la unidad de observación para varios estudios relacionados con la economía popular por el mercado ahí ubicado. Podemos señalar los trabajos de Yépez (2014), Kingman (2012), Espín (2009), Cuminao (2006) y Crain (2001), que miran temas de género, identidades, itinerarios de los vendedores, problemáticas sociales, etc. No obstante, nuestra investigación se diferencia porque no se limita al estudio de la economía popular sino mira una esfera hasta ahora poco tratada: el análisis de esa parte más organizada de dicha economía como es la economía popular y solidaria.

En ese sentido, este trabajo desborda el estudio de caso ya que muestra elementos que permiten comprender cómo una economía popular pasa a ser una economía popular y solidaria en contextos urbanos. Para interpretar este fenómeno se utilizaron las reflexiones teóricas provenientes del sentido sustantivo de lo económico (Polanyi, 1976), de la economía popular y solidaria (Coraggio, 2013) y de la economía popular (Razeto, 1993; Sarria y Tiriba, 2004; Diéguez, 2009). De esta manera, no solo se visibilizan aquellas estrategias económicas motivadas por la sociedad civil que les permiten resolver sus problemas y satisfacer necesidades sin recurrir al aporte estatal o del sector privado, sino que se proporciona información indispensable para el Estado en sus diferentes niveles y que puede ser útil para la formulación de políticas públicas. Esto último en el marco de un país que ha reconocido constitucionalmente, desde el año 2008, a su sistema económico como social y solidario, y a la economía popular y solidaria como su subsistema.

La estructura del artículo está dividida en tres apartados: el primero que expone los elementos teóricos que utilizamos para comprender e interpretar el caso de San Roque; el segundo muestra un breve contexto histórico acerca de la conformación de la economía popular en Quito, sobre todo de San Roque, por parte de indígenas urbanos inmigrantes; el tercero, y último, expone la transición de las prácticas económicas populares a las populares y solidarias, profundizando en tres casos: una caja de ahorro y crédito de una asociación de comerciantes, una cooperativa de ahorro y crédito, y una cooperativa de vivienda. A esto se une la explicación metodológica y las respectivas conclusiones.

\section{Metodología}

Para establecer la metodología de esta investigación se parte de la premisa que para investigar las experiencias económicas que se alejan de cánones establecidos por el sistema económico empresarial capitalista imperante, es necesario considerar metodologías poco utilizadas en materia económica -la cual ha sido tratada más en su dimensión cuantitativa- que permitan unir nuevamente el conocimiento de los actores, sus subjetividades e intersubjetividades con aquel producido por las universidades e institutos de investigación (Jácome, 2016). Así, la metodología cualitativa contribuyó a alcanzar lo señalado, puntualmente dos métodos: la etnografía y el estudio de caso. 


\section{DE ECONOMÍA POPULAR A ECONOMÍA POPULAR Y SOLIDARIA EN QUITO: EL CASO DE LOS INDÍGENAS URBANOS INMIGRANTES DEL BARRIO SAN ROQUE}

En lo que se refiere a la etnografía, es entendida como el "método concreto o un conjunto de métodos donde el investigador participa abiertamente o de manera encubierta en la vida diaria de las personas durante un periodo, y observa los comportamientos, escucha las conversaciones, hace preguntas y acopia datos útiles para la investigación" (Hammersley y Atkinson, 1995). En este sentido, desarrollamos los siguientes pasos:

1. Observación y participación abierta en la vida cotidiana de los actores.- En este punto se realizaron varias visitas al sector de San Roque durante los años 2016 y el primer trimestre del 2017. En primera instancia se efectuó una observación preliminar de los fenómenos; es decir, se determinó que en San Roque se habían establecido cooperativas y cajas de ahorro y crédito y que estas organizaciones, en un número considerable, estaban administradas por indígenas, lo cual llamó la atención ya que, mediante conversaciones coloquiales con personas que viven en el sector, se determinó que estas organizaciones estaban conformadas por indígenas que inmigraron en años pasados.

2. Visitas a varios emprendimientos populares que permitieron un acercamiento a las organizaciones sociales y económicas del barrio.- Se generó confianza con sus directivos, quienes permitieron realizar la investigación. De esta manera, se logró profundizar el estudio en dos cooperativas: Ahorro y Crédito "Alli Tarpuk Ltda." y de Vivienda "Condominios la Nueva Esperanza"; además, se pudo acceder a una Caja de Ahorro y Crédito de la Asociación "Central Primero de Mayo". Es importante señalar que en esta fase se contó con el apoyo de investigadores del Instituto de la Ciudad del Municipio de Quito, que nos pusieron en contacto con directivos del barrio San Roque.

3. Aplicación de instrumentos de investigación.- Se entablaron conversaciones con los directivos por dos finalidades: la primera, para obtener información necesaria para comprender el contexto histórico de la conformación de los casos detectados y demás información importante; y también para que, por intermedio de ellos, se pueda generar confianza con los demás miembros de las organizaciones. Después de haber obtenido cierto grado de confianza con los demás actores, se nos permitió realizar entrevistas, un grupo focal y el acercamiento con otras personas que reforzaron, mediante testimonios, la información recolectada. Para la aplicación de las herramientas de investigación se solicitaron permisos verbales para registrar las entrevistas y tomar fotografías.

4. Comprensión e interpretación teórica de los casos.- Considerando que la metodología cualitativa exige dos acciones: primero comprender los fenómenos sociales, y posterior interpretarlos, se realizó el ejercicio de analizar la información obtenida en los pasos anteriores; de manera inmediata, se apreció que los hechos con los que nos enfrentábamos no podían ser interpretados desde enfoques teóricos de la economía formal, esto nos condujo a acudir a conceptos más relacionados con un enfoque sustantivista, así tenemos: economía popular y economía popular y solidaria; a estos términos unimos un concepto operativo: indígenas urbanos migrantes. Luego de la obtención de resultados, se plantearon algunas conclusiones. Para la fase de escritura, toda la información recolectada fue transcrita y sistematizada. Al momento de pasar el audio a texto escrito se tuvo cuidado de respetar las formas de hablar de las personas, considerando que también se buscó que el texto muestre las voces de los actores. 
En lo que respecta al estudio de caso, otro de los métodos utilizados nos permitió describir y analizar con profundidad los elementos de una realidad específica con el fin de identificar problemáticas y proporcionar posibles soluciones. Para su aplicación consideramos la propuesta de Caracciolo y Foti (2003) y Páez (2013) y la adaptamos a nuestra investigación, considerando los siguientes elementos: datos y diagnóstico de la organización, actividades, operación y presencia de la solidaridad; verificación de que los actores de la economía popular transitaron a una organización de economía popular y solidaria, y constatación de la práctica de los principios cooperativos, de la economía popular y solidaria, y del Buen Vivir. A fin de aplicar este método, se construyó una matriz que abarcó los puntos señalados en la cual se colocó las informaciones producto del trabajo etnográfico que permitió evidenciar que los casos analizados cumplen con parámetros para ser considerados como prácticas económicas populares y solidarias.

A todo lo indicado, se articuló la información producto de la investigación documental. Se revisaron trabajos publicados en la Revista Cuestiones Urbanas, del Instituto de la Ciudad del Municipio de Quito, en los cuales se conocieron nombres y ubicaciones claves acerca del lugar donde se encontraba la información inicial necesaria. También se revisaron trabajos como tesis y publicaciones, muchas ya referenciadas en la introducción, realizadas en Flacso-Ecuador, Universidad Andina Simón Bolívar y el Instituto de Altos Estudios Nacionales.

Es importante en este punto también hacer referencia a ciertos limitantes que se presentaron al desarrollar la investigación. Primer limitante: la construcción de la confianza, este tema retrasó los tiempos establecidos para el trabajo de campo, ya que no se obtuvo acceso inmediato a las organizaciones, fue necesario el apoyo del Instituto de la Ciudad del Municipio de Quito y visitas insistentes hasta mostrar que la investigación no constituía un peligro para las organizaciones. Vinculado con lo anterior se encuentra el limitante del acceso a fuentes primarias; si bien se autorizó desarrollar el trabajo etnográfico, no ocurrió lo mismo con la revisión de libros de actas de las organizaciones, que contienen información sobre su origen; por eso en el trabajo priman los relatos de los entrevistados. Un tercer limitante fue la intervención de la Superintendencia de Economía Popular y Solidaria en una cooperativa de ahorro y crédito del barrio, que terminó con el proceso de liquidación de esta organización. Este último suceso, incluso nos obligó a abandonar los objetivos vinculados a las finanzas éticas y solidarias, que implicaba información sobre depósitos, créditos, activos, entre otros, ya que las organizaciones se negaron a facilitar dichos datos, por ese motivo se profundizó en la aplicación de entrevistas. 


\section{Economía popular, economía popular y solidaria e indígenas urbanos inmigrantes: el marco teórico de la investigación}

Varios son los conceptos y las teorías usadas para denotar prácticas económicas que se alejan de los fines de aquella economía hegemónica de mercado que impera en el mundo. Esta diversidad se presenta a lo largo del planeta; Latinoamérica no es la excepción. Así, conceptos y realidades como economía social y solidaria, economía popular, economía popular y solidaria, socioeconomía de la solidaridad, economía de la solidaridad, economía comunitaria, entre otros, son algunos de los conceptos y prácticas que revelan lógicas económicas en las cuales el lucro no es el fin.

En ese contexto, cuestionar el mismo sentido de qué es lo económico supone teorizar la esencia de la economía y analizar las vías que toman diversos actores en el proceso económico. Karl Polanyi (1976) analiza el sentido de lo económico y lo diferencia en dos significados, el formal y el substantivo:

El significado substantivo de lo económico deriva de la dependencia del hombre, para su subsistencia, de la naturaleza y de sus semejantes. Se refiere al intercambio con el medio ambiente natural y social, en la medida en que este intercambio tiene como resultado proporcionarle medios para su necesaria satisfacción material.

El significado formal de lo económico deriva del carácter lógico de la relación medios-fines, tal como aparece en palabras como "económico" (barato) o "economizar» (ahorrar). Se refiere a la concreta situación de elegir, especialmente a la elección entre los distintos usos de los medios que provoca la insuficiencia de estos medios. Si denominamos lógica de la acción racional a las reglas que determinan la elección de los medios, podemos denominar esta variante de la lógica con el término improvisto de economía formal.

(Polanyi, 1976: 155)

Ante tal diferenciación, estamos frente a dos vías de hacer y pensar la economía. La economía vista desde un sentido formal, nos conlleva a pensar en que los seres humanos, solamente, asistimos a un sistema de intercambios en el cual existe un problema económico en la asignación de recursos escasos para fines diversos. En tal sentido, la idea de economizar (ahorrar; o económico es igual a barato, como decía Polanyi) se refiere a la elección y cálculo de usos de recursos (siempre escasos) que permitan obtener la maximización del beneficio en tanto el alcance de resultados 0 , lo que es lo mismo, obtener un mayor beneficio al menor costo posible. Esta idea, supuestamente única, basada en el cálculo racional (maximización de beneficio) es la conceptualización de la economía de mercado, instaurada hace varios siglos atrás con el nacimiento de la Revolución Industrial. Frente a esta lógica de acción racional, que se reduce a la búsqueda del máximo beneficio, la institución que organizaría un sistema económico donde todos sus actores (utilitaristas) están actuando de forma racional sería 
una economía de mercado, de un mercado autorregulado, con un sistema de precios establecidos por la ley de la oferta y la demanda.

En ese escenario (mercado) se producen varios rasgos que definen al llamado homo economicus; es decir, las personas, en este modelo económico de mercado, deben comportarse como seres individualistas, egoístas, competitivos, utilitaristas a fin de obtener el máximo beneficio, siempre medido por una riqueza basada en la acumulación del dinero y factores de producción en pocas manos. De esta forma, "si un actor se comporta irracionalmente (de acuerdo a valores o costumbres sin calcular para maximizar, etc.) el mercado lo rectificará con sus castigos y, en el límite, lo excluirá condenándolo al hambre" (Coraggio, 2013: 9). Frente a esta afirmación, es preciso mencionar que existen actores económicos que no solo buscan el lucro o subordinan la maximización del beneficio por una lógica de conseguir el sustento para todos y el medio ambiente que los rodea. Es decir, estos actores irracionales (en el sentido de que actúan en contraposición del único fin -lucro sin fin- de la lógica de mercado), que por cierto son sustantivistas, se preocupan por el bienestar de los otros y del entorno que los rodea (comunidad y medio ambiente).

De ese modo, el sentido sustantivo de lo económico tiene una lógica que se basa en el sustento de los seres humanos; es decir, el fin de la economía no sería, solamente, obtener el máximo beneficio luego de un cálculo (matemático) procedimental que guía a los individuos a optimizar sus comportamientos (formalismo económico); sino asegurar que todos los miembros de una sociedad tengan acceso al sustento. Así, Polanyi nos refiere a otra racionalidad, que se relaciona con la reproducción de la vida de la sociedad mediante el sustento que debería otorgar una economía que garantice la provisión de bienes materiales y que satisfaga las necesidades de todos.

En consecuencia, y concordando con Polanyi, nos encontramos frente a una economía de carácter heterogéneo que no tiene una sola vía de análisis. Su sentido, en relación con hacer y pensar la economía, no es considerar el lucro como su único fin, sino buscar el sustento de todos y de las nuevas generaciones. Estos sentidos u otras formas de producir han sido verificables en las economías empíricas y su visibilización la debemos, de cierto modo, a las investigaciones de carácter histórico y antropológico. Por ejemplo, Polanyi apoyado en estas ciencias humanas y sociales determinó la existencia de cuatro principios de integración social de la economía: reciprocidad, redistribución, administración doméstica y el intercambio; por lo que señala que en ninguna economía el mercado, como parte del principio del intercambio, tuvo predominio sobre los otros como se pretende ahora señalar.

Ahora bien, siguiendo a Coraggio (2013) considerar a la economía como mixta, permite visibilizar a otras formas económicas y no solo al mercado empresarial capitalista. El autor señala que empíricamente la economía está conformada por tres sectores agregados: a) economía empresarial capitalista, basada en una racionalidad de reproducción sin límites del capital, crecientemente monopolizada, organizada por empresas capitalistas y grupos de control; b) economía pública, regida por la acumulación de poder político y los requisitos de gobernabilidad del sistema, organizada por sistemas administrativos burocráticos y pautada por normas legales; $y, c$ ) economía popular, basada en la reproducción 


\section{DE ECONOMÍA POPULAR A ECONOMÍA POPULAR Y SOLIDARIA EN QUITO: EL CASO DE LOS INDÍGENAS URBANOS INMIGRANTES DEL BARRIO SAN ROQUE}

biológica y social de sus miembros, organizada mediante unidades domésticas (UD), redes de ayuda mutua, asociaciones; así como mediante intercambios mercantiles o de reciprocidad.

Esta economía mixta reconoce la presencia de otras lógicas económicas, no solo las determinadas en la economía moderna (empresarial privada, pública y popular), sino también aquellas que emergen de la intersección de estos campos económicos que conforman otras formas económicas, por ejemplo, la economía solidaria. Esta última, que se refiere a "el sector de la economía que se rige interna y externamente por relaciones de cooperación, intercambio, financiamiento y consumo solidarios" (Coraggio, Arancibia y Deux, 2010: 13), se muestra conjugable con los tres sectores de la economía. Así, el subsector de economía popular, que no siempre por sí sola es solidaria, al interactuar con la economía solidaria conforman el estadio económico denominado economía popular y solidaria, el cual es reconocido en el Ecuador y se muestra como base para alcanzar un sistema económico social y solidario.

Enfocándonos en el concepto de economía popular (EP), vemos que este ha sido utilizado desde el último tercio del siglo anterior (Razeto, Klenner y Ramírez, 1990; Sarria y Tiriba, 2004; Coraggio, 1998) para "referirse a las actividades desarrolladas por los que fueron excluidos o nunca consiguieron ingresar al mundo del trabajo asalariado" (Sarria y Tiriba, 2004: 175). También, el concepto ha sido relacionado con aquellos emprendimientos por cuenta propia conformados por trabajadores que no se encontraban satisfechos acerca de sus ingresos provenientes de sus bajos salarios y encontraban en la economía popular el complemento a los mismos. Por otra parte, ha sido considerado para definir al subsistema conformado por trabajadores de diversas actividades en las cuales se incluye "toda la producción de bienes y servicios (fuerza de trabajo como mercancía y como valor de uso, producción para el autoconsumo, producción de servicios, etc.) que permiten la reproducción de la vida de sus miembros" (Diéguez, 2009: 252). Para el caso de este estudio, se acoge esta última definición, porque se relaciona con el concepto de economía mixta, explicado anteriormente; además, nos permite tratar el tema de economía solidaria y su papel en la adjetivación de la economía popular, que conlleva a hablar de una economía popular y solidaria.

En Ecuador la economía popular y solidaria fue reconocida como una forma de organización económica del sistema económico social y solidario mediante la Constitución de la Republica del año 2008, y está conformado por el sector cooperativo, asociativo y el comunitario. Para la legislación ecuatoriana, esta economía es comprendida como:

La forma de organización económica, donde sus integrantes, individual o colectivamente, organizan y desarrollan procesos de producción, intercambio, comercialización, financiamiento y consumo de bienes y servicios, para satisfacer necesidades y generar ingresos, basadas en relaciones de solidaridad, cooperación y reciprocidad, privilegiando al trabajo y al ser humano como sujeto y fin de su actividad, orientada al buen vivir, en armonía con la naturaleza, por sobre la apropiación, el lucro y la acumulación del capital.

(Ley Orgánica de Economía Popular y Solidaria, 2011, art. 1) 
Este concepto señala que el proceso económico (producción, distribución, circulación, financiamiento y consumo) será basado en prácticas solidarias a fin de satisfacer necesidades y generar ingresos, pero con una racionalidad sustantiva de relacionamiento equitativo entre los seres humanos y la naturaleza y no únicamente con la finalidad de lucro. Esta es una economía en la que prima una racionalidad, en palabras de Hinkelammert (2009), reproductiva. Esto por el hecho de que varios individuos o colectivos trabajan mancomunadamente para resolver el problema de la obtención del sustento y se garantice la reproducción de la vida.

Dejando a un lado a la definición legal de la economía popular y solidaria, se tiene que esta economía opera mediante la producción para el autoconsumo individual o comunitario, el ingreso del trabajo asalariado y de la venta de la producción, los ingresos que permiten el acceso al producto del trabajo de otros, y la obtención de donaciones de diverso tipo, transferencias monetarias y subsidios de costos y precios respecto a los valores de mercado (Coraggio, Arancibia y Deux, 2010: 11). Además, está conformada por las familias y comunidades que organizan su trabajo en función de sus necesidades, vendiendo la fuerza de trabajo 0 aplicando sus capacidades al trabajo para el autoconsumo; los microemprendimientos por cuenta propia, familiar o asociativa, que producen para la venta en el mercado las diversas asociaciones. Frente a lo señalado, la economía popular y solidaria presenta una racionalidad que busca lograr la reproducción ampliada de la vida de sus miembros y esto implica "minimizar el uso del trabajo, usar eficientemente los recursos que escasamente obtiene en el mercado con su ingreso" (Coraggio, 2013: 23).

En definitiva, esta economía constituye el cruce tanto de la economía popular como de la economía solidaria, señalando una particularidad: "la asociación libre o la preexistencia de comunidades", es decir la asociatividad, que constituye "un nivel secundario de solidaridad que excede al del grupo doméstico"; en consecuencia, si bien la legislación en Ecuador incluye como parte de la economía popular y solidaria a los emprendimientos individuales y familiares, en nuestro caso, siguiendo a Coraggio, Arancibia y Deux (2010), consideramos las experiencias que estén "asociados solidariamente con otros similares" (p. 15).

\section{Una categoría operativa: indígenas urbanos inmigrantes}

En articulación con las categorías de economía popular y economía popular y solidaria tenemos el de indígenas urbanos inmigrantes. Según Mercedes Prieto (2004) en Ecuador de la década de 1930 se pensaba al sujeto indígena como aquel que se ubicaba en las zonas rurales, hablaba lenguas nativas, vestía y habita en viviendas peculiares; sin embargo, los espacios urbanos albergaban a trabajadores, comunidades y parcialidades indígenas que rompían con dicha concepción. Estos grupos indígenas de la ciudad ya no presentaban los elementos que permitían identificarlos como indios: vestimenta, residencia y lengua, por lo que fueron reconocidos como indios urbanos o indios urbanizados. 


\section{DE ECONOMÍA POPULAR A ECONOMÍA POPULAR Y SOLIDARIA EN QUITO: EL CASO DE LOS INDÍGENAS URBANOS INMIGRANTES DEL BARRIO SAN ROQUE}

Para el caso de la urbe quiteña, esta población estaba compuesta por dos grupos claramente diferenciados: aquellos que llegaban a la ciudad como producto de procesos migratorios y que se dedicaban a actividades como el comercio, albañilería, cargadores, entre otros; y los indígenas cuyas comunidades estaban ubicadas en la mancha urbana o sus alrededores, y que se trasladaban constantemente al centro de la urbe con el fin de desarrollar servicios como aguateros, barrenderos, servidoras domésticas, etc., y en la noche retornaban a sus comunidades para pernoctar; por lo tanto, ambos grupos construyeron distintas relaciones sociales, económicas y sociales con la ciudad (Jácome, 2015: 35).

Como se señaló al inicio de este trabajo, nuestro centro de atención es el primer grupo, para cuya identificación se ha considerado la categoría de "indígena urbano inmigrante". Es necesario indicar que existen varios estudios en América Latina sobre los indígenas urbanos que habitan en la ciudad como producto de procesos migratorios, por ejemplo: Weiss, Engelman y Valverde (2013) que presentan un interesante estado de la cuestión acerca de indígenas urbanos provenientes de los pueblos mapuche, qom y guaraní, ubicados en ciudades de Argentina; Sánchez (2002) analiza la migración indígena hacia la ciudad de México y su relación con el mundo del trabajo; Motta (2010) presenta un estudio etnográfico referente a indígenas urbanos provenientes de los pueblos quichuas, inga, kofán, guambiano, nasa y yanaconas que se han radicado en la ciudad de Cali, Colombia y su relación con la economía popular; Pérez (2002 y 2007) provee información acerca de la vida de los indígenas en las ciudades de México en aspectos económicos, culturales, sociales e identitarias; Camus (1998 y 2002) expone sobre los indígenas urbanos en ciudad de Guatemala; mientras que Barragán (2009) describe el comercio informal propiciado por los indígenas aymara en La Paz; no obstante, las investigaciones señaladas utilizan el término general de "indígena urbano". En este contexto, este trabajo se diferencia por que utiliza la categoría indígena urbano inmigrante, pues se considera que tiene un sentido operativo que permite explicar las prácticas económicas de un grupo específico de ese conglomerado reconocido como indígenas urbanos de la ciudad de Quito.

Llegado a este punto, es indispensable explicar con mayor detalle qué se entiende por indígena urbano inmigrante, considerando, que los trabajos desarrollados alrededor de este grupo no realizan la distinción entre los inmigrantes y no inmigrantes. De este modo, se los puede reconocer como aquellos que constituyen una identidad cultural y étnica que se avizora alrededor de las grandes ciudades, y que su residencia en la ciudad es producto de la inmigración campo-ciudad; es decir, el traslado de indígenas desde sus comunidades de origen hacia las ciudades, en donde, de manera transformada, reproducen sus identidades.

Para el caso de Quito, en los barrios donde se han ubicado reproducen sus costumbres, las mujeres utilizan indumentaria tradicional, algunos son bilingües y otros solo hablan español, mantienen fiestas, trabajo colectivo, gobierno comunitario, entre otras. Ejemplo de lo indicado se puede observar en los barrios El Inca, donde habitan grupos otavaleños; La Victoria, con los panzaleos; y San Roque, habitado por indígenas de la sierra centro del país, especialmente, del pueblo Puruhá. 
Lo anterior conlleva a definir al indígena inmigrante que vive en las ciudades en los términos propuestos por David Robichaux (2005); es decir, "ser indio" significa pertenecer a una comunidad con una organización social basada en el sistema de cargos, en el cual sus obligaciones para con la comunidad constituyen un importante marcador que los diferencian del resto de la población; en otras palabras, va más allá de los marcadores étnicos usuales de idioma e indumentaria, que no aplican en estas poblaciones. Esta definición permite mirar a los indígenas urbanos inmigrantes alejados de estereotipos que lo identifican como pobres, rurales, que usa vestimenta tradicional, que deben habitar en sus suscripciones territoriales, y tiene un idioma que pocos logran entender (Gómez, 2008).

Bajo este paraguas teórico (economía popular, economía popular y solidaria e indígenas urbanos inmigrantes) se interpretó la transición de una economía popular a una popular y solidaria en el barrio San Roque. En términos amplios, este permitió tener un acercamiento a las prácticas económicas desarrolladas por los indígenas urbanos inmigrantes que se establecieron en el sector de San Roque, pero no desde un sentido formal de lo económico, sino desde un sentido sustantivista. Para definir las diferencias entre la economía desarrollada a partir de la década de 1970 por los indígenas urbanos con la que desarrollan actualmente, se hizo uso de los conceptos de economía popular y economía popular y solidaria, considerando en esta última su elemento distintivo: la asociatividad, que en este caso direccionó a la identificación y análisis del cooperativismo y asociacionismo. Se advierte que, si bien el trabajo se concentra en la economía popular y solidaria, el proceso de transición que conllevó al origen de la misma no desvaneció la economía popular; al contrario las dos conviven y se articulan. En los siguientes apartados se presenta los detalles de lo aquí indicado.

\section{Resultados}

\subsection{San Roque: contexto histórico de un espacio de economía popular}

En las ciudades de Ecuador, como en otras ciudades de la región, en el transcurrir de las décadas del siglo XX, se acrecentaron formas económicas populares por el incremento de la población que supuso la migración campo-ciudad. Carrión (2017) afirma que a inicios de la década de1960, América Latina dejó de ser una región con mayor presencia de la población en lo rural y empezó a crecer la población en el ámbito urbano. Este proceso se evidencia al constatar que las urbes que albergaban en 1950 el $41 \%$ de la población pasaron al 82\% en el 2010.

Los focos de atracción en Ecuador fueron Quito y Guayaquil, donde migraron, entre otros grupos, indígenas de la sierra centro del país, acrecentando demográfica y económicamente las urbes. Varios fueron los factores por los cuales migraron, específicamente, en la década de 1970: la Reforma Agraria 


\section{DE ECONOMÍA POPULAR A ECONOMÍA POPULAR Y SOLIDARIA EN QUITO: EL CASO DE LOS INDÍGENAS URBANOS INMIGRANTES DEL BARRIO SAN ROQUE}

de 1964 y la capitalización del trabajo en los campos; la crisis agrícola; la conformación del Estadonación del Ecuador que está basado en el sistema neoliberal capitalista; el disponer, tanto indígenas como mestizos, de apenas dos hectáreas o menos de tierra en el campo hizo que no pudiesen competir con la producción agrícola a gran escala que provenía del Perú; el auge petrolero que desembocó en el crecimiento urbano; la concentración de las actividades en los polos económicos del país (Quito y Guayaquil); el cambio que se buscó en transitar de una economía que se fundaba en el sector primario (agricultura y ganadería) a una que se dirigiera a los sectores secundario y terciario como la industria y los servicios; entre otros, fueron los detonantes de las migraciones campo-ciudad.

La nueva población en busca del sustento engrosó una economía popular que se mantiene hasta la actualidad, pero no solo se quedaron con iniciativas económicas individuales, sino transitaron a prácticas solidarias para satisfacer necesidades de vivienda, inclusión al ahorro, al crédito y, por ende, al trabajo. Un espacio en la ciudad de Quito, donde se evidencia este fenómeno social, es el barrio San Roque.

Desde siglos pasados, San Roque ha sido una zona de comercio. Espinosa Apolo (2009) señala que a partir de la primera mitad del siglo XVII, este barrio sufrió un incremento poblacional y urbano, probablemente producto de su cercanía a los principales mercados. "En la misma plaza parroquial se había formado un mercadillo; mercados que le imprimieron al barrio un dinamismo económico inusitado" (p. 70). Incluso, desde hace 120 años funciona en el sector el mercado San Francisco (antes conocido como San Roque). También existen: el mercado mayorista y minorista San Roque, establecido en 1981; la Plataforma Central Primero de Mayo, establecida en 1975; y un amplio comercio desarrollado en locales comerciales y también ambulante que se ubica alrededor de los mercados y calles aledañas. Por esto no resulta extraño comprender por qué campesinos e indígenas inmigrantes buscaron establecer su residencia en este sector.

San Roque fue, y continua siendo, uno de esos espacios de acogida y de oportunidades económicas para propios y extraños; por lo cual, empieza a configurarse como un sector de la ciudad que aglutina a migrantes indígenas que se dedican a la economía popular. En tal contexto, un indígena que migró en la década de 1970 a la ciudad señala:

[...] con mis padres éramos muy pobres en Pilahuín, no teníamos ni tierrita ni ganado para vivir, más también eran mis padres analfabetos. [...] yo vine acá (San Roque) desde que yo tuve cinco años, estamos hablando más o menos del año de 1975. Mi historia es muy triste, mi madre, analfabeta pero muy inteligente, vendíamos -como antes decían ajeros- ajos, yo era atrás de ella desde wawito (niñito) empezamos por el mercado de San Roque que era donde es ahora el de abajo de San Francisco; asi íbamos, más luego, por otros mercados: el de Iñaquito, la Ofelia, Comité del Pueblo, Mayorista, o sea que he sido de todos los mercados; pero todo empezó aquí en San Roque [...].

(E: J.C., 2016) ${ }^{1}$

1.- Las entrevistas se referencian de la siguiente manera: E: Entrevista, J. C.: nombre y apellido del entrevistado; 2016 es el año en el que se realizó la entrevista. 
De esta manera, los indígenas recién llegados a San Roque empezaron a nutrir un comercio popular ya existente en la zona. A propósito, el primer contacto que tenían los campesinos e indígenas migrantes con la capital era la avenida 24 de mayo, en ese tiempo reconocido como un espacio de comercio y terminal de buses (Espín, 2012).

Para la década de 1970, Quito ingresó en un proceso para convertirse en Primer Patrimonio Cultural de la Humanidad. Las políticas de patrimonialización no se hicieron esperar, pero las mismas se suscitaron con un enfoque de "higienización" o limpieza del comercio popular que se desarrollaba en las calles del Centro Histórico de Quito, en especial la av. 24 de Mayo y San Roque (Cando, 2015; Ortega, 2015). Estos intentos incitaron a varios comerciantes, para que se organicen y luchen por el reconocimiento de un espacio de comercio. Un claro ejemplo es la conformación de la Asociación de Pequeños Comerciantes "Central Primero de Mayo" en el año 1975; a decir de esta plataforma de comercio popular, su dirigente comenta sobre su conformación:

[...] migrantes de las provincias conformaron la Plataforma, principalmente de las zonas de Cotopaxi, Tungurahua y de Chimborazo; y por el tema de las frutas, por personas de la costa. El punto de ubicación central había sido lo que hoy se conoce como la 24 de Mayo, inclusive ahí, me parece, que por los años cincuenta y sesenta, era ahí la zona del terminal, una especie de terminal terrestre, justo ahí donde le dicen la zona del "águila", ahí había sido la zona donde venían los carros de las provincias. Entonces la gente, como venía a la ciudad se quedaba ahí, y como todo punto de terminal terrestre es sitio de ventas, entonces ahí se aglutinaban y con eso ellos empezaban a comercializar y por la tradición se quedaron en la 24 de Mayo.

(E: F.C., 2016)

Acerca de las posiciones de lucha frente a las políticas de patrimonialización, una socia fundadora indica:

Ahorita ya tengo 60 años, vine de 18 años a Quito. Yo vendía afuera en la calle, vendía comidita, arrocito preparado era; yo vine de la provincia de Cotopaxi, cantón Salcedo vine. Era llenita la feria en la avenida 24 de Mayo, ahí era la venta, donde decimos la "puerta de sol", ahí era. Así, ya no nos dejaban vender afuera en la calle, teníamos problemas con el Municipio por eso; entonces, nos ayudaron a organizarnos los estudiantes de la Universidad Central, también los señores del MPD (Movimiento Popular Democrático). Al señor Lenin Rosero (militante del MPD), a él le rogamos que nos ayude. Así nos organizamos y a base de mingas 2 logramos recuperar este espacio de la plataforma.

(E: P.CH., 2016)

2.- Minga, se refiere a una forma de trabajo conjunto para conseguir algo. También conocida como minka, trabajo colectivo voluntario con fines de utilidad social o de carácter recíproco, que fomenta el ahorro, estimula el trabajo y potencia la producción, como por ejemplo, la construcción de un canal de riego o de una edificación de carácter sagrado. 


\section{DE ECONOMÍA POPULAR A ECONOMÍA POPULAR Y SOLIDARIA EN QUITO: EL CASO DE LOS INDÍGENAS URBANOS INMIGRANTES DEL BARRIO SAN ROQUE}

En la década de 1980 los comerciantes fueron removidos de la av. 24 de mayo, y uno de los lugares que fueron destinados para su reubicación fue el mercado San Roque, para lo cual el Municipio de Quito construyó la infraestructura en 1981. Es así como se han mantenido, desde décadas pasadas, los indígenas inmigrantes practicando la economía popular junto a otros comerciantes que son de Quito y sus alrededores.

A propósito de la diversidad de las formas económicas populares que fueron y siguen siendo desarrollados por indígenas urbanos inmigrantes y otros grupos en San Roque, tenemos: "el comercio mayorista de productos comestibles, ventas minoristas ambulantes, el comercio de ropa y otros artículos, los saloneros (dueños de salones y comedores populares), la sastrería, zapatería, el servicio doméstico, cargar o estibar, desgranar" (Maldonado, 2012: 48). Es interesante mostrar otra clasificación, que se puede unir a la anterior, propuesta por el Instituto de la Ciudad de Quito (2015) en la cual se señala una diversidad de las ocupaciones de los comerciantes del mercado San Roque, tales como: vendedores de mariscos, cargadores, desgranadores, mayoristas, rodeadoras, artesanos, costureros, mueblistas, vendedores de muebles, vendedores de puestos fijos, vendedores de comidas preparadas y recicladores.

Actualmente en este sector se puede observar a comunidades indígenas específicas que reproducen ciertas costumbres que las practicaban en sus territorios, tal es el caso de la comunidad de Colta de la provincia de Chimborazo, ubicada en la calle Bolívar, entre Imbabura y Chimborazo, que incluso se extiende hacia la calle Quiroga del barrio San Roque. Ellos se han apropiado del espacio y han desarrollado estrategias para considerarse como propios en ese lugar. De este modo, muchos de los indígenas urbanos que migraron desde la comunidad de Colta poseen viviendas propias, tienen sus negocios relacionados a una economía popular, pero con principios comunitarios, poseen cajas y cooperativas de ahorro y crédito, han instalado sus iglesias evangélicas; incluso, son generadores de confianza ya que los vecinos -personas que ya habitaban ahí y son quiteños que no se desplazaron a otros barrios por la llegada de los indígenas en la década de 1970-, los consideran personas de gran confianza. Es decir, han reproducido su territorio y comunidad en la ciudad capital.

Por la migración permanente se han configurado "redes familiares o de ayuda mutua" (Moscoso, Ortega y Sono, 2015: 115), compuestas por familiares, amigos, compadres y conocidos que han llegado a conformar barrios enteros, como es el caso de La Cocha en el sur de Quito (Demon, 2012); incluso, estas comunidades provenientes de la sierra central del país han constituido un tejido poblacional importante en San Roque.

Por otra parte, es importante señalar que esta población ha sido excluida tanto en ámbitos sociales como económicos, por ejemplo: no tienen acceso al sistema financiero convencional, sus trabajos son precarios (sin seguridad social), falta de vivienda en condiciones dignas; también han sido presa de formas agiotistas, conocida en Ecuador como chulco, expresión que se refiere a préstamos con tasas usureras y con extorsión en el momento del cobro. 
Las dificultades les han motivado a establecer formas económicas populares y solidarias para cubrir necesidades que no lograban solucionar de forma individual. Mediante la unión de esfuerzos y recursos, sin intención de generalizar, alcanzaron una forma de inclusión al sistema financiero, a la vivienda, a la seguridad social, incluso a alejarse del chulco, entre otros aciertos. Actualmente, se aprecian cooperativas, cajas de ahorro y crédito y asociaciones que permite aseverar que existe una transición de una economía popular a una economía popular y solidaria, tema que profundizaremos en el siguiente apartado.

\subsection{Transiciones económicas contadas desde sus actores: del emprendimiento individual a prácticas solidarias más complejas en San Roque}

Los indígenas urbanos inmigrantes de San Roque han suscitado varias lógicas económicas y sociales que entrañan prácticas solidarias. Desde su misma llegada, algunos indígenas experimentaron los lazos de solidaridad que habían conformado en sus comunidades de origen, que aportaron en la configuración de redes de ayuda mutua en la ciudad. Aquí un relato:

Yo soy de la provincia de Cotopaxi, cantón Salcedo y me acuerdo que todita la 24 de Mayo era lleno de venta de ropa y vendían cosas viejas; incluso todito era de venta de muebles también, y era el mercado donde es ahora, el de San Francisco, había mucho indígena. [...] ahí me contacté con mi hermana que ya vivía en San Roque haciendo chompa de cuero con marido, verá; eran artesanos en cuero. Ahí me vine a ayudar con eso porque era para un pedido de la Empresa Eléctrica Quito y antes daban chompa de cuero daban [...] Me conocen años en San Roque y vi como esto siempre ha sido comercial, y vienen, pues, los demás indígenas y se quedan [...] incluso se unen los de Chimborazo, incluso, bastante por iglesia evangélica, son bien unidos verá, y compran hasta casas, verá que viven, pero luego se van a otras o compran entre familias [...] hasta veo que hasta cooperativa de ahorro y crédito han formado, pero casi recién no más, son bien unidos verá.

(E: G.G., 2016)

Este relato muestra un nivel de solidaridad impulsada por familiares para que los indígenas recién llegados se inserten en la economía popular. Esta economía va tomando cierta complejidad al punto de transitar a una economía popular y solidaria mediante la conformación de cooperativas o asociaciones de comerciantes que aportan en gran medida a la economía de los trabajadores. Sin embargo, esta transición no ha conllevado a la desaparición de la economía popular; al contrario, las dos se articulan y los actores se mueven entre ambos campos económicos como estrategias que les permiten la reproducción ampliada de la vida.

Otras formas de relación socioeconómica, fundamentadas en lógicas solidarias en el sector son las asociaciones de comerciantes, que han motivado la creación de organizaciones de economía popular y solidaria como es el caso de las cajas de ahorro y crédito, entre otras formas. Estas lógicas aso- 


\section{DE ECONOMÍA POPULAR A ECONOMÍA POPULAR Y SOLIDARIA EN QUITO: EL CASO DE LOS INDÍGENAS URBANOS INMIGRANTES DEL BARRIO SAN ROQUE}

ciativas han permitido a los actores, muchos de ellos indígenas inmigrantes, resolver diferentes problemas como: la lucha contra el desplazamiento del mercado popular en San Roque; la conformación de fondos solidarios para tener acceso al ahorro, al crédito, la seguridad social, protección, entre otras necesidades. En este escenario se conoce que en San Roque existen alrededor de 23 asociaciones de comerciantes (Fundación Museos de la Ciudad, 2013).

Respecto de las organizaciones de la economía popular y solidaria (OEPS), en la investigación de campo y documental se han identificado un total de dieciocho OEPS entre financieras y no financieras. Varias de ellas se encuentran registradas en el ente rector que las regula (Superintendencia de Economía Popular y Solidaria), mientras que otras no se encuentran registradas; es decir, nacen de la voluntad del pueblo para cubrir su necesidades de trabajo, vivienda y financiamiento, pero que no necesariamente se encuentran inscritas en el órgano regulador.

Así, para comprender de mejor manera el proceso de transición de una economía popular a una economía popular y solidaria que aludimos en este trabajo, a continuación se detallan tres casos: una caja de ahorro y crédito, una cooperativa de ahorro y crédito, y una cooperativa de vivienda.

\section{Caso A. Caja de ahorro y crédito de la Asociación Primero de Mayo: visos de solidaridad en la economía popular}

La Caja de Ahorro y Crédito se ubica en el sector de San Roque, en la intersección de la av. 24 de Mayo y la calle Chimborazo, en una oficina que está dentro de la Plataforma de la Asociación Jurídica de Pequeños Comerciantes "Central Primero de Mayo". Está conformada, en buena parte, por personas que migraron a Quito en la década de 1970, aunque la caja nació en el año 2005 (E: F. C., 2016). Actualmente se conforma por cuarenta socias y socios provenientes de diferentes provincias de la sierra centro del país y de zonas periurbanas de Quito, incluso otros cantones de la provincia de Pichincha. Un 96\% son mujeres y el restante 4\% son hombres. La caja es de carácter cerrado; es decir, solamente pertenecen a esta organización los miembros de la Asociación, por lo cual, su alcance es local. Manejan una contabilidad básica que les permite registrar las entradas y salidas de dinero, asimismo, "se realizan comitivas de fiscalización para los arqueos de caja y para las auditorías, lo cual permite transparentar el flujo de la caja en Asamblea General" (E: F.C., 2016).

Jurídicamente se sustenta en el Código del Trabajo del Ecuador, art. 441, en el cual se menciona que el Estado protegerá a las asociaciones de trabajadores, cuando persigan, entre otros fines, "el apoyo mutuo mediante la formación de cooperativas o cajas de ahorro". También, esta organización se articula con la cooperativa de ahorro y crédito "Manantial de Oro Limitada"; todo esto con el fin de otorgar mayores valores mediante el crédito a las socias y socios. De esta forma, la caja puede conceder hasta un máximo de USD 200,00 en crédito (aunque puede ser flexible y otorgar préstamos de hasta USD 400,00); y por medio de la cooperativa pueden acceder a valores sobre los USD 500,00. Además, al estar las socias y socios vinculados a la caja de ahorro y crédito, constituye una carta de 
garantía para solicitar préstamos en la cooperativa. Entonces, el principal problema que intenta resolver esta articulación de la caja con la cooperativa es evitar que las personas se sometan al sistema chulco, que es una actividad ilícita muy desarrollada en espacios urbanos de los mercados populares, como se relata a continuación:

El chulco es una práctica diaria aquí en San Roque; por eso, principalmente existe la Caja [...]. No sé cómo se llame formalmente al chulco. Esos tipos cobran demasiados intereses en los préstamos. Imagínate, por USD 500,00 estar pagando USD 30,00 mensuales, y hacerlo por tres años, y los USD 500,00 ahí muertos; es algo terrible. Además que la actitud de estos también es por la belicosidad y la prepotencia del que te presta; con la caja eso es lo que se trata de hacer, es evitar que las socias se involucren con el chulco.

(E: F.C., 2016)

También, muchas de las socias y socios solicitan créditos productivos, ya que varias de ellas y ellos producen en las cercanías de Quito y venden sus productos en San Roque:

Hay socias que producen y traen a vender acá. Producen pollos, las señoras que venden alfalfa, las que producen choclos y de los granos. Vienen a la caja y les pregunto: ¿Ustedes van a sembrar?, me dicen que sí, me piden USD 300,00 o USD 400,00 y se le otorga el crédito; luego ellas dan fe de que usaron el crédito para la producción y, aunque no me creas, vienen trayendo y me dicen: tome esto, es lo que saque de la siembra que hice con el crédito, $y$ te regalan alimentos.

(E: F.C., 2016)

Es importante resaltar, que la Asociación como tal, desarrolla otras lógicas económicas solidarias muy interesantes:

- Fondos de seguridad social: dinero que es aportado y gestionado por los propios comerciantes. Mediante un aporte mensual se conforma un fondo; estos valores son destinados a los socios y las socias de la Asociación de comerciantes que requieren de salud, como por ejemplo para someterse a una cirugía o para la compra de medicinas.

- Fondos mortuorios: de la misma manera, mediante un aporte mensual se forma un fondo que será destinado para los miembros de la Asociación de comerciantes o para sus familiares cercanos que fallecen y requieren de dinero para afrontar los gastos funerales.

- Fondos para obtener seguridad: ante la necesidad de verse resguardados de la delincuencia del sector, los miembros de la Asociación aportan dinero para el contrato de guardias que velan por la seguridad de todos.

- Conformación de cajas de ahorro y crédito: consiste en la formación de un fondo, gestionado por las/los asociadas/dos y que les permite tener acceso al ahorro y crédito, para diversos fines, como por ejemplo: gastos de educación de sus hijos, préstamos para producción o compra de productos que comercializan en San Roque, gastos de salud, entre otras necesidades. 
Acerca de la aplicación de los principios de economía popular y solidaria (EPS), presenta los siguientes:

\section{Cuadro 1. Presencia de principios de la EPS en el caso A}

\begin{tabular}{|c|c|}
\hline Principios delimitantes & Aplicación \\
\hline $\begin{array}{l}\text { Prelación del trabajo sobre el capi- } \\
\text { tal y de los intereses colectivos } \\
\text { sobre los individuales }\end{array}$ & $\begin{array}{l}\text { La caja de ahorro y crédito se propone ayudar al desarrollo económico de las } \\
\text { socias y socios a través del ahorro y otorgamiento de créditos para alejarlos del } \\
\text { chulco, apoyar con créditos de consumo para problemas familiares que se sus- } \\
\text { citan en enfermedad y época escolar. Se coloca al trabajo y el bien colectivo sobre } \\
\text { las individualidades. }\end{array}$ \\
\hline $\begin{array}{l}\text { Asociación voluntaria, equitativa y } \\
\text { respeto a la identidad cultural }\end{array}$ & $\begin{array}{l}\text { El ingreso a la caja es voluntaria y abierta para las/los socias/os de la Plataforma } \\
\text { Central Primero de Mayo. Sus miembros son indígenas y mestizos. }\end{array}$ \\
\hline Autogestión y autonomía & $\begin{array}{l}\text { La caja de ahorro y crédito cuenta con la administración de los propios asociados } \\
\text { constituida por un presidente, tesorero, secretario, gerente y comités de fiscali- } \\
\text { zación. Además, cuenta con procesos de transparencia visibilizados en la asam- } \\
\text { blea general de socios. No existe injerencia de instituciones u organismos } \\
\text { externos. }\end{array}$ \\
\hline $\begin{array}{l}\text { Participación económica solidaria } \\
\text { y distribución equitativa de utilida- } \\
\text { des o excedente }\end{array}$ & $\begin{array}{l}\text { Las socias y socios pueden participar de los fondos de la caja mediante la soli- } \\
\text { tud de un crédito y sin garante; lo que prima es la confianza. Incluso se realizan } \\
\text { préstamos sin intereses cuando un miembro se encuentra en condiciones de vul- } \\
\text { nerabilidad económica o de salud. }\end{array}$ \\
\hline $\begin{array}{l}\text { Educación, capacitación y comu- } \\
\text { nicación }\end{array}$ & $\begin{array}{l}\text { Existe capacitación cooperativa cuando las socias o los socios solicitan un prés- } \\
\text { tamo, más aún cuando solicitan un crédito mayor en la Cooperativa de Ahorro y } \\
\text { Crédito Manantial de Oro. }\end{array}$ \\
\hline $\begin{array}{l}\text { Cooperación e integración del } \\
\text { Sector Económico Popular y Soli- } \\
\text { dario }\end{array}$ & $\begin{array}{l}\text { Se encuentra articulada con una Cooperativa de Ahorro y Crédito denominada } \\
\text { "Manantial de Oro". La caja sirve, también, como generadora de confianza y } \\
\text { garantía. }\end{array}$ \\
\hline $\begin{array}{l}\text { Compromiso social, solidario, co- } \\
\text { munitario y ambiental }\end{array}$ & $\begin{array}{l}\text { Existe un compromiso social con los miembros al ser beneficiados con pequeños } \\
\text { créditos productivos o de consumo. El tema solidario se refleja acerca de la fle- } \\
\text { xibilidad de la morosidad, la entrega de préstamos para que las/los socias/os } \\
\text { paguen al chulco, el no cobro de intereses cuando las personas están en condi- } \\
\text { ciones de vulnerabilidad; hay reciprocidad porque los excedentes que generan } \\
\text { las socias y socios de la Asociación son ahorrados en la caja y luego se reali- } \\
\text { zan los créditos. En lo ambiental, los socios de la caja realizan mingas de lim- } \\
\text { pieza en la zona de la plataforma de comercialización de productos. }\end{array}$ \\
\hline
\end{tabular}

FUENTE: Investigación de campo, entrevistas (2016). 


\section{Caso B. "Para eso trabajamos, para incluir a la gente": la Cooperativa de Ahorro y crédito Alli Tarpuk Ltda.}

Esta cooperativa se encuentra ubicada en el barrio de San Roque y cuenta con una sucursal ubicada en la parroquia de Calderón, norte de Quito. Está conformada por alrededor de dos mil quinientos socios. El $80 \%$ corresponde a mujeres en situaciones de vulnerabilidad como: madres solteras, tercera edad, viudas y en condiciones de pobreza, cuyas actividades se desarrollan en torno a la economía popular del sector de San Roque y otros lugares. El 20\% restante se constituye por hombres que desarrollan actividades económicas populares; también forman parte asociaciones de comerciantes como: 23 de Abril del mercado San Roque, Asociación de Comerciantes de Comidas del Centro Comercial Montufar, Asociación de Comerciantes del Mercado Artesanal, Asociación de Comerciantes del Centro Comercial Quitus; iglesias evangélicas; y varias cajas de ahorro y crédito (E: G. G., 2017).

Acerca de su alcance, su gerente habla de todo el territorio de la ciudad de Quito. No solamente son socios indígenas de la provincia de Chimborazo que residen y desarrollan sus actividades económicas en la zona de San Roque, sino que su servicio se extiende a personas del sur y norte de la ciudad, Guayllabamba, Puéllaro y todas las personas que deseen ingresar, siempre y cuando acepten con respeto los principios comunitarios establecidos en la cooperativa. La organización cuenta con dos oficinas ubicadas en San Roque y Calderón, poseen mobiliario suficiente para atender a sus clientes. Sus trabajadores son altamente capacitados respecto a estudios formales (universidad) y en principios comunitarios. En su mayoría, los trabajadores son indígenas.

Está legalmente registrada en la Superintendencia de Economía Popular y Solidaria como parte del segmento cinco $^{3}$. Las actividades son el ahorro y el crédito con sentido comunitario y enfocado en el tema de género, como lo señala un socio:

Nosotros más que solo dedicarnos al ahorro y al crédito, la cooperativa Alli Tarpuk es comunitaria porque tiene un territorio, alrededor vemos casas, iglesias, garaje, locales que son de los compañeros indígenas de la provincia de Chimborazo, y para todos ellos y algunos vecinos es que funciona la cooperativa y más para ayudar a mujeres vulnerables. Por ejemplo, hay una señora que tiene 80 años que no firma, no habla bien el español, trabaja en la calle, ella cada dos meses pide USD 400,00 y nosotros le damos; eso no pasaría en la banca tradicional, imposible. Para eso trabajamos, para incluir a la gente.

(E: G.G., 2017)

3.- En Ecuador, las cooperativas de ahorro y crédito, según su capital en millones de dólares, están categorizadas en cinco segmentos; así, segmento 1: mayor a 80 millones; 2: entre 20 y 80 millones; 3: entre 5 y 20 millones; 4: entre 1 y 5 millones; $y, 5$ : hasta 1 millón, aquí se incluyen las cajas de ahorro y crédito, bancos comunales y cajas comunales. 


\section{DE ECONOMÍA POPULAR A ECONOMÍA POPULAR Y SOLIDARIA EN QUITO: EL CASO DE LOS INDÍGENAS URBANOS INMIGRANTES DEL BARRIO SAN ROQUE}

Entre los requisitos que exige para otorgar préstamos es que el socio tenga como máximo 65 años de edad; sin embargo, otorgan los préstamos a personas con mayor edad a la establecida, porque su finalidad es la inclusión. Sobre el principio de solidaridad, el gerente de la cooperativa manifiesta:

El tema de solidaridad se enfoca por la ayuda mutua, por ejemplo hay personas que no tienen como iniciar su emprendimiento, la banca tradicional no da crédito. La mayor expresión de solidaridad está ahí, por ejemplo: se casó una chica de la cuarta generación ${ }^{4}$ de aquí, de la comunidad, que tiene 16 años, por la garantía de los padres que son fundadores de la cooperativa de ahorro y crédito, le otorgamos 4 mil dólares para que puedan emprender, la banca tradicional no daría a alguien de 16 años pero nosotros le ayudamos y esperamos que nos pague. La solidaridad se manifiesta con los vecinos, que son quiteños, y se manifiesta a través de sus ahorros porque son gente con poder económico, ellos traen su dinero porque nosotros reflejamos confianza por la organización, con ese dinero ayudamos con créditos a la gente más pobre.

(E: G.G., 2017)

También existen prácticas solidarias cuando fallece alguna persona, los directivos se organizan y aportan, no con dinero, sino con comida, un quintal de arroz, etc. Asimismo, el gerente de la organización nos habla de la reciprocidad ya que ellos "dan a los vecinos pero sin esperar nada a cambio, pero luego ellos vienen y ahorran en nuestra cooperativa, así damos crédito a quienes necesitan".

(E: G.G., 2017)

La cooperativa está articulada con una red de cooperativas pero solo para la capacitación, por ejemplo en temas de riesgo, finanzas, colocación, recuperación, contabilidad, tributación, entre otros temas. También se articula con cajas de ahorro y crédito, asociaciones de trabajadores e iglesias evangélicas. Entre los problemas que intenta resolver la cooperativa se encuentra el tema del chulco, que lo combaten mediante su vinculación con una caja de ahorro y crédito impulsada por ellos mismos. De esta manera, se otorgan créditos sin muchos requisitos a mujeres, personas de la tercera edad, madres solteras, vendedoras ambulantes, entre otras, que necesitan de un préstamo para emprender su negocio y cubrir necesidades. La caja de ahorro y crédito permite agilitar la tramitología en la otorgación de los préstamos equiparándose con la velocidad con la que los chulqueros dan los préstamos, ya que la cooperativa se demora por las formalidades en las que debe incurrir.

4.- La persona entrevistada señala que las personas que conforman la comunidad de Colta establecidas en San Roque, se encuentran en la cuarta generación. Así, afirma que los primeros indígenas inmigrantes que llegaron a San Roque en 1970, son la primera generación que se dedicaban a trabajos como: cargadores o estibadores, limpiabotas, entre otros oficios. Luego tenemos los que nacieron a finales de los 70 e inicios de los 80 , son la segunda generación, quienes se dedican mucho más al comercio con puestos fijos, tiendas, bodegas, entre otros. La tercera generación es de los años 90 , y tienen emprendimientos de la economía popular y economía popular y solidaria; trabajan en relación de dependencia y algunos han estudiado. A los nacidos en la década del 2000 los considera como la cuarta generación, que son más académicos, según su afirmación, pues se dedican a estudiar y algunos a trabajar. (E: G. G., 2017). 
Respecto a la transición a formas más solidarias tenemos un relato que permite visualizar el proceso:

La historia de la cooperativa inicia hace más de cuarenta años. Nuestros padres, que son la primera generación que vino a San Roque eran estibadores, se dedicaban a cargar, otros limpiaban zapatos; hasta ahora hay algunos que siguen de estibadores o limpiando zapatos. Ellos vieron la oportunidad, hace más de cuarenta años, de ahorrar para poder acceder al crédito. Con mucho orgullo somos los excluidos; $y$ asi formaron un fondo rotativo con 25 personas de Chimborazo; incluso hay un acta de 1980 que dice que iniciaron con un aporte de 45 sucres cada uno y así reunieron y se daban préstamos, pero solo a una persona y hasta que pague podían dar a otra. Pasan los años y en 1999 ya tenían como 5 millones de sucres, pero viene la dolarización y se quedan con 200 dólares, que era un valor insignificante para lo que tenían. Siguieron, en el año 2005 se transforman en caja de ahorro y crédito y ya tenían 6.000 dólares. En el 2009 crean la cooperativa, el 13 de abril de ese año, ya tenían más de 12 mil dólares y así ha crecido el fondo; incluso ahora contamos con más de 2.500 socios.

(E: G.G., 2017)

Acerca de los principios de economía popular y solidaria que presenta, tenemos (Cuadro 2, página siguiente): 


\section{Cuadro 2. Presencia de principios de la EPS en el Caso B}

\begin{tabular}{|c|c|}
\hline Principios delimitantes & Aplicación \\
\hline $\begin{array}{l}\text { Prelación del trabajo sobre el capi- } \\
\text { tal y de los intereses colectivos } \\
\text { sobre los individuales }\end{array}$ & $\begin{array}{l}\text { El trabajo está sobre los intereses de acumulación, esto se manifiesta en que los } \\
\text { créditos que otorga son destinados para que emprendan las personas vulnera- } \\
\text { bles, como por ejemplo las mujeres que no tienen garante ni encajes. Más allá } \\
\text { de verificar la capacidad de pago, la organización tiene la finalidad de ayudar para } \\
\text { que exista una inclusión en el trabajo y al sistema financiero por parte de los más } \\
\text { necesitados. }\end{array}$ \\
\hline $\begin{array}{l}\text { Asociación voluntaria, equitativa y } \\
\text { respeto a la identidad cultural }\end{array}$ & $\begin{array}{l}\text { La cooperativa no tiene restricciones para integrar a nuevos socios/as. No obs- } \\
\text { tante, deben ser capacitados en valores por el Consejo de Sabios para que sean } \\
\text { íntegros y no corrompan en la cooperativa. }\end{array}$ \\
\hline Autogestión y autonomía & $\begin{array}{l}\text { Presenta una organización sui generis. No tiene la clásica organización de una } \\
\text { cooperativa (consejos de administración, vigilancia, gerencia, etc.), sino que existe } \\
\text { un Consejo de Sabios (amautas), que dan sus puntos de vista acerca de la ima- } \\
\text { gen interna y externa de la cooperativa; además, participan en la toma de deci- } \\
\text { siones. En conflictos internos, como la morosidad, actúa este Consejo con la } \\
\text { justicia indígena que, en su contexto, se relaciona más con la mediación comu- } \\
\text { nitaria o justicia ancestral. Entre las sanciones que aplica tenemos: no tomarles } \\
\text { en cuenta en Navidad o para ser directivos, exclusión de las reuniones y de la } \\
\text { dirección de la iglesia, no se les otorga créditos por cinco años. }\end{array}$ \\
\hline $\begin{array}{l}\text { Participación económica solidaria } \\
\text { y distribución equitativa de utilida- } \\
\text { des o excedente }\end{array}$ & $\begin{array}{l}\text { Se realiza un trabajo democrático en el cual se invita a todos a participar en la } \\
\text { toma de decisiones. Existe distribución de los excedentes de nuevos créditos, y } \\
\text { apoyo a madres solteras, ancianos y agasajos navideños en la comunidad de } \\
\text { Colta, Chimborazo. }\end{array}$ \\
\hline $\begin{array}{l}\text { Educación, capacitación y comu- } \\
\text { nicación }\end{array}$ & $\begin{array}{l}\text { Existe capacitación, tanto comunitaria como técnica. El Consejo de Sabios enseña } \\
\text { sobre puntualidad, reciprocidad, honestidad; en cambio, en temas técnicos se } \\
\text { miran temas de riesgos y financieros. }\end{array}$ \\
\hline $\begin{array}{l}\text { Cooperación e integración del } \\
\text { Sector Económico Popular y } \\
\text { Solidario }\end{array}$ & $\begin{array}{l}\text { La integración que mantienen es con una caja de ahorro y crédito de la comuni- } \\
\text { dad y de la iglesia. }\end{array}$ \\
\hline $\begin{array}{l}\text { Compromiso social, solidario, co- } \\
\text { munitario y ambiental }\end{array}$ & $\begin{array}{l}\text { Entre sus políticas se encuentra el apoyo a las personas más vulnerables, por } \\
\text { ejemplo con mujeres pobres, madres solteras, ancianas, jóvenes que requieren } \\
\text { de un crédito para emprender. También realizan condonaciones de deudas para } \\
\text { casos extremos, como la muerte de un socio; para esto existe un fondo rotativo } \\
\text { de los sabios de la comunidad. }\end{array}$ \\
\hline
\end{tabular}

FUENTE: Investigación de campo, entrevistas (2016). 


\section{Caso C. "No tenían donde vivir": el rol de la Cooperativa de Vivienda "Condominios la Nueva Esperanza"}

Esta cooperativa constituye una casa de tipo colonial que se ubica en las calles Bolívar y Chimborazo, la cual fue modificada para otorgarle una estructura de condominio para albergar a 120 familias, alrededor de 600 personas. Cuenta con 120 departamentos con una medida promedio de 77 metros cuadrados de construcción cada uno, estos se asientan en un área de terreno de 6.200 metros cuadrados. Tienen todos los servicios básicos. Además, por el incremento de los socios, poseen una "precooperativa"5 de ahorro y crédito llamada "El Sembrador" (Bravo, Calva, Jaramillo, Montalvo y Saint Jean, 2015).

La Cooperativa de Vivienda no ha sido registrada ante la Superintendencia de Economía Popular y Solidaria. Sus socios han decidido llamar al proyecto habitacional como cooperativa sin necesidad de registrarlo, y su objetivo principal es brindar soluciones de vivienda a sus asociados que trabajan en el sector de San Roque, sus alrededores o que pertenecen a la comunidad. Esta cooperativa surgió por el esfuerzo de sus asociados que se encontraban con problemas graves en cuanto a la vivienda y, por medio de sus principios comunitarios, lograron obtener el acceso a la misma. Así lo describe uno de los cooperativistas:

Nosotros somos indígenas de la provincia de Chimborazo, de la comunidad San Bartolo. Nos dedicamos al comercio del sector de San Roque, algunos cargadores, otros vendedores de verduras, así varios trabajos, incluso en los locales de los Centros Comerciales del Ahorro. Ya vivimos hace más de 40 años algunos por aquí. Muchos se encontraban en la pobreza sufriendo por la vivienda, no tenían donde vivir. Así, viendo esto, con siete amigos más formamos un proyecto de ayuda y atención social; pudimos gestionar y comprar primero la casa patrimonial y luego ir haciendo los departamentos. Por el año1992 pasó eso. Fue sin la ayuda de nadie ni pública, social, ni nada; es trabajo autogestionado.

(E: J.Y., 2016)

Entre los principios de economía popular y solidaria que practican se encuentran (Cuadro 3):

5.- Es la forma como han denominado a esta estructura financiera local; otras personas del sector las denominan cajas de ahorro y crédito. 


\section{Cuadro 3. Presencia de principios de la EPS en el Caso C}

\begin{tabular}{|c|c|}
\hline Principios delimitantes & Aplicación \\
\hline $\begin{array}{l}\text { Prelación del trabajo sobre el capi- } \\
\text { tal y de los intereses colectivos } \\
\text { sobre los individuales }\end{array}$ & $\begin{array}{l}\text { Existe un interés colectivo para dar solución a la falta de una vivienda propia y en } \\
\text { condiciones dignas. Así, una parte de los indígenas de la provincia de Chimborazo } \\
\text { que vinieron en la década de 1970, que realizan sus actividades económicas y } \\
\text { viven en San Roque han logrado mediante la solidaridad cubrir la necesidad de } \\
\text { vivienda, mediante esta cooperativa. }\end{array}$ \\
\hline $\begin{array}{l}\text { Asociación voluntaria, equitativa y } \\
\text { respeto a la identidad cultural }\end{array}$ & $\begin{array}{l}\text { La adhesión a la cooperativa se ha realizado de forma voluntaria. El único requi- } \\
\text { sito está centrado en "la adopción, no opcional, de los principios fundamentales } \\
\text { que nos une como comunidad: el respeto, la solidaridad y la unidad" (E: J.Y., } \\
\text { 2015). }\end{array}$ \\
\hline Autogestión y autonomía & $\begin{array}{l}\text { El acceso a la vivienda o para formar la cooperativa ha sido mediante la auto- } \\
\text { gestión y organización de quienes la conforman. Entre ellos toman las decisiones } \\
\text { sobre construcción, mantenimiento, destino de los ingresos que obtienen de algu- } \\
\text { nas viviendas que arriendan. }\end{array}$ \\
\hline $\begin{array}{l}\text { Participación económica solidaria } \\
\text { y distribución equitativa de utilida- } \\
\text { des } 0 \text { excedente }\end{array}$ & $\begin{array}{l}\text { Todos los socios participan de los beneficios de la vivienda. Ellos, mediante apor- } \\
\text { tes mensuales, han formado un fondo común para arreglo de la fachada de los } \\
\text { departamentos y de la casa. Asimismo, han logrado obtener un espacio que lo } \\
\text { alquilan como estacionamiento; estos ingresos y otros que provienen del arriendo } \\
\text { de algunos departamentos son distribuidos entre los socios o para beneficio comu- } \\
\text { nitario. }\end{array}$ \\
\hline $\begin{array}{l}\text { Educación, capacitación y comu- } \\
\text { nicación }\end{array}$ & $\begin{array}{l}\text { Existen formas de capacitación acerca de trabajo comunitario por parte de las } \\
\text { personas con mayor edad, pero no es continuo; no se practica ese principio con } \\
\text { mayor intensidad. La comunicación se desarrolla mediante la rendición de cuen- } \\
\text { tas de los ingresos y trabajos realizados en el condominio; todo esto previo a una } \\
\text { toma de decisiones en conjunto o democrática. }\end{array}$ \\
\hline $\begin{array}{l}\text { Cooperación e integración de Sec- } \\
\text { tor Económico Popular y Solidario }\end{array}$ & $\begin{array}{l}\text { La cooperativa de vivienda tiene relación con una precooperativa de ahorro y cré- } \\
\text { dito conformada por los socios. }\end{array}$ \\
\hline $\begin{array}{l}\text { Compromiso social, solidario, co- } \\
\text { munitario y ambiental }\end{array}$ & $\begin{array}{l}\text { El compromiso es comunitario porque se preocupan de que las personas, que no } \\
\text { tienen vivienda, puedan acceder a la misma mediante la cooperativa. Respecto } \\
\text { del ambiente realizan mingas de limpieza. }\end{array}$ \\
\hline
\end{tabular}

FUENTE: Investigación de campo, entrevistas, 2016. 


\section{Conclusiones}

La investigación de las formas económicas populares y su transición a lógicas populares y solidarias es importante para tener conocimiento sobre cómo los grupos indígenas pueden, no desde una forma individual sino asociativa, solucionar el problema de la satisfacción de sus necesidades de bienes, servicios legítimos y en condiciones dignas. Estas economías difieren de los conceptos y principios que rigen a las prácticas de las empresas privadas capitalistas y de la economía pública; por lo tanto, para su comprensión e interpretación son indispensables otros cuerpos teóricos, y aquí es donde el sentido sustantivo de lo económico, la economía popular y, la economía popular y solidaria se presentan como aquellas categorías que pueden permitir ese acercamiento a la realidad de las prácticas económicas desarrolladas por las sociedades históricamente excluidas, como es el caso de los indígenas urbanos que constituyeron los sujetos de nuestra pesquisa.

Centrando la discusión en los indígenas urbanos, a fin de no homogeneizarlos y analizar sus prácticas económicas, fue necesario utilizar los cuerpos teóricos antes aludidos; además, diferenciar entre los indígenas que habitan la ciudad como producto de los procesos de migración interna que se aceleró en América Latina durante en el siglo XX, de aquellos que han habitado en el sitio ahora ocupado por las ciudades incluso antes de la llegada de los ibéricos, y que por el proceso de crecimiento urbano fueron físicamente incorporados a la urbe. Esta diferenciación resultó necesaria frente a que los dos grupos se encuentran en la ciudad de Quito, espacio que delimita este estudio, y cuyas relaciones sociales, culturales, políticas y económicas con la ciudad son distintas. De este modo, se determinó una categoría operativa: "indígenas urbanos inmigrantes", con la finalidad de no explicar los procesos de transición de una economía popular a una más solidaria del conjunto de indígenas urbanos, sino de un determinado grupo: los inmigrantes.

Esta población estableció su vivienda en la ciudad, específicamente en el barrio San Roque a partir de la década de 1970, y pasaron a formar parte de una economía popular que se venía desarrollando en Quito, contribuyendo a diversificarla con nuevas prácticas económicas como tiendas de abarrotes, comedores, dulcerías, y varios servicios en los mercados. Sin embargo, los indígenas urbanos inmigrantes originaron una forma económica más organizada: la economía popular y solidaria, la cual existe actualmente y que está atravesada por principios de solidaridad, democracia participativa, transparencia, reciprocidad, ayuda mutua, etc. Por lo indicado, se asevera que en San Roque se produjo un proceso que condujo a que la economía popular transite a formas económicas solidarias, sin que esto implique que la primera haya desaparecido; no obstante, estas nuevas formas tienen como fin garantizar, de manera asociativa, aspectos materiales como el acceso al trabajo, al ahorro, al crédito, a la vivienda, a la salud, entre otros, y también, siendo esto novedoso, aspectos simbólicos producto de sus relaciones comunitarias que desarrollaban en sus suscripciones territoriales y que 


\section{DE ECONOMÍA POPULAR A ECONOMÍA POPULAR Y SOLIDARIA EN QUITO: EL CASO DE LOS INDÍGENAS URBANOS INMIGRANTES DEL BARRIO SAN ROQUE}

ahora las reproducen en su nuevo territorio: la ciudad; como la confianza, el gobierno comunitario, el trabajo colectivo, la ayuda mutua.

Lo anterior se evidencia en la caja de ahorro y crédito, cooperativa de ahorro y crédito y cooperativa de vivienda, que constituyeron los estudios de caso presentados. Estas experiencias demuestran que sus prácticas están atravesadas por principios que las delimitan como de economía popular y solidaria, por ejemplo, haciendo un ejercicio de articulación y explicación entre los principios presentes en los tres casos: los socios constituyen indígenas urbanos inmigrantes, aunque admiten también a personas del barrio o alrededores del mercado de San Roque, que de manera voluntaria se han asociado; su gestión interna es democrática lo que implica que la toma de decisiones se la realice de manera consensuada mediante el mecanismo de un socio es igual a un voto o por intermedio de sus representantes como ocurre en la cooperativa de ahorro y crédito que ha conformado un Consejo de Amautas; su objetivo es tanto social como económico, y esto implica que su fin sea la satisfacción de las necesidades de los miembros o de la colectividad, por tanto, sus prácticas pasan por encima del lucro, por eso es más importante que sus socios cuenten con vivienda, créditos, capacitación, salud, entre otros, que solo liquidez; la distribución del excedente no es estrictamente en función del capital que cada uno haya colocado en la organización, sino de decisiones participativas que miran tanto el beneficio individual como el colectivo. Las tres experiencias cumplen con su objetivo económico y social mediante una actividad económica y económico-financiera con el cual proveen de manera regular de bienes y servicios a sus socios y a la comunidad; por último, disponen de autonomía de decisión.

Para cerrar, lo tratado a lo largo de este trabajo constituye información indispensable para los hacedores de políticas públicas, ya que solo conociendo las particularidades de estas economías se pueden formular políticas que respondan a las necesidades de los actores, y no terminen desvirtuando sus prácticas o desestructurándolas. Esto, además, puede ser útil para plantear políticas públicas diferenciadas: rurales, urbanas, periurbanas, de economía popular, de economía popular y solidaria, y sobre todo aquellas que contribuyan a transitar de una economía popular a una más solidaria a fin de contribuir a democratizar la economía y ponerla realmente al servicio de la sociedad como parece ocurrir en el barrio San Roque de Quito. 


\section{Referencias bibliográficas}

BARRAGÁN, R. (2009): "Más allá de lo mestizo, más allá de lo aymara: organización y representaciones de clase y etnicidad". En: E. Kingman. (Comp.), Historia social urbana. Espacios y flujos, Quito: Flacso-Ecuador / Ministerio de Cultura del Ecuador, 293-322.

BRAVO, R., CALVA, Y., JARAMILLO, O., MONTALVO, Y. \& SAINT JEAN, F. (2015): Cooperativa de vivienda La Nueva Esperanza, Trabajo de fin de cátedra, IAEN, Quito, Ecuador, Inédito.

CAMUS, M. (2002): Ser indígena en la ciudad de Guatemala, Guatemala: Flacso.

CANDO, F. (2015): Asociación jurídica de pequeños comerciantes plataforma Central 1ro. de Mayo, 40 años de historia, Quito: Inédito.

CARACCIOLO, M. \& FOTI, M.P. (2003): Economía Solidaria y Capital Social: contribuciones al desarrollo local, Buenos Aires: Paidós.

CARRIÓN, F. (2017): "La ciudad ilegal en América Latina", El País.

Recuperado de http://www.goo.gl/wJ4mVw.

CORAGGIO, J.L. (1998): Economía urbana: la perspectiva popular, Quito: Abya-Yala / Ildis / FlacsoEcuador.

CORAGGIO, J.L. (2013): Fundamentos de Economía Social y Solidaria, Quito: Instituto de Altos Estudios Nacionales [IAEN].

CORAGGIO, J.L., ARANCIBIA, M.I. \& DEUX, M.V. (2010): Guía para el mapeo y relevamiento de la Economía Popular Solidaria en Latinoamérica y Caribe, Lima: Grupo Red de Economía Solidaria del Perú - GRESP.

CRAIN, M. (2001): "La interpretación de género y etnicidad: nuevas autorepresentaciones de la mujer indígena en el contexto urbano de Quito". En: G. Herrera (Coord.), Antología y Género, Quito: Flacso-Ecuador / Junta de Andalucía, 353-381.

CUMINAO, C. (2006): Memoria e identidad de las vendedoras kichwa y mestizas del mercado de San Roque en la ciudad de Quito (Tesis de maestría), Flacso-Ecuador, Quito.

DE LA CADENA, M. (2004): Indígenas mestizos: raza y cultura en el Cusco, Lima: IEP Ediciones.

DEMON, J. (2012): "Una comunidad de migrantes indígenas en la ciudad de Quito: caracteríticas sociales y laborales". En: J. Erazo. (Coord.), Políticas de empleo y vivienda en Sudamérica, Quito: Flacso-Ecuador / Clacso / Instituto de la Ciudad, 169-191. 


\section{DE ECONOMÍA POPULAR A ECONOMÍA POPULAR Y SOLIDARIA EN QUITO: EL CASO DE LOS INDÍGENAS URBANOS INMIGRANTES DEL BARRIO SAN ROQUE}

DIÉGUEZ, R. (2009): "Macroeconomía y Economía Popular". En: J.L. Coraggio, J.L. Laville y A. Cattani (Coords.), Diccionario de la otra economía, Buenos Aires: Universidad Nacional de General Sarmiento, 247-253.

ESPÍN, M.A. (2009): La presencia indígena en la ciudad: la construcción del indígena urbano en el barrio de San Roque (Tesis de maestría), Flacso-Ecuador, Quito.

ESPÍN, M.A. (2012): "Los indígenas y el espacio citadino. Los lugares de la vivienda". En: E. Kingman (Ed.), San Roque: indígenas urbanos, seguridad y patrimonio, Quito: Flacso-Ecuador / Heifer Ecuador, 101-134.

ESPINOSA, M. (2009): Insumisa vecindad: memoria política del barrio San Roque, Quito: Quito Eterno.

HAMMERSLEY, M. \& ATKINSON, P. (1995): Ethnography, New York: Routledge.

HINKELAMMERT, F. \& MORA, H. (2009): "Por una economía orientada hacia la reproducción de la vida", Iconos Revista de Ciencias Sociales, 33, 39-49.

INSTITUTO DE LA CIUDAD DE QUITO (2015): Conociendo Quito: San Roque y sus áreas de influencia, primeros hallazgos de investigación en un territorio complejo, Quito: Instituto de la Ciudad de Quito.

JÁCOME, V. (2011): Economía política e identidades en las comunas peri-urbanas de Quito (Tesis de Maestría), Flacso-Ecuador, Quito.

JÁCOME, V. (2015): "Mujeres indígenas urbanas y comunas en Quito del siglo XX: representaciones sociales y relaciones económicas con la urbe", Revista Tsafiqui, 7.

Recuperado de https://revistas.ute.edu.ec/index.php/tsafiqui/article/view/272.

JÁCOME, V. (2016): "Economía popular y solidaria en la comuna San José de Cocotog, Quito: estudio de la producción del cuy", Revista Economía, 41.

Recuperado de http://www.goo.g//Km3WRg [15/12/2017].

KINGMAN, E. (2006): La ciudad y los otros: Quito 1860-1940: higienismo, ornato y policía, Quito: Flacso-Ecuador.

KINGMAN, E. (2012): "San Roque y los estudios sociales urbanos". En: E. Kingman (Ed.), San Roque: indígenas urbanos, seguridad y patrimonio, Quito: Flacso-Ecuador / Heifer Ecuador, 7-20.

MALDONADO, G. (2012): "Matices y texturas de la identidad cultural étnica en contextos urbanos: el caso de los kichwas de Chimborazo". En: E. Kingman (Ed.), San Roque: indígenas urbanos, seguridad y patrimonio, Quito: Flacso-Ecuador / Heifer Ecuador, 37-77.

MINCHOM, M. (2007): El pueblo de Quito1690-1810: demografía, dinámica sociorracial y protesta popular, Quito: Fonsal.

MOSCOSO, R., ORTEGA, J. \& SONO, A. (2015): "Mercado San Roque: migración, trabajo y redes sociales", Revista Cuestiones Urbanas, 3(2), 101-137. 
ORTEGA, J. (2015): "La rehabilitación de la avenida 24 de Mayo y la fórmula 'regeneración + patrimonio"', Revista Cuestiones Urbanas, 3(1), 151-181.

PÁEZ, J.R. (2013): "Importancia del Balance Social para las organizaciones de la economía popular y solidaria: Desarrollo metodológico de la SEPS". En: J.L. Coraggio, R. Muñoz, C. Naranjo, H. Jácome, M.J. Ruiz y J. Páez (Eds.), Estudios sobre Economía Popular y Solidaria, Quito: Superintendencia de Economía Popular y Solidaria, 145-198.

POLANYI, K. (1976): "El sistema económico como proceso institucionalizado". En: M. Godelier (Comp.), Antropología y economía.

Recuperado de https://www.ddooss.org/libros/maurice_godelier.pdf.

PRIETO, M. (2004): Liberalismo y temor: imaginando los sujetos indígenas en el Ecuador postcolonial, 1895-1950, Quito: Flacso-Ecuador.

RAZETO, L., KLENNER, A. \& RAMÍREZ, A. (1990): Las organizaciones económicas populares 19731990, Santiago de Chile: PET.

RAZETO, L. (1993): De la economía popular a la economía de solidaridad en un proyecto de desarrollo alternativo, Santiago de Chile: PET.

ROBICHAUX, D. (2005): "Identidades cambiantes: indios y mestizos en el suroeste de Tlaxcala", Revista Relaciones 104: Nosotros y los otros: dispositivos de identidad, vol. XXVI, 68-69.

REPÚBLICA DEL ECUADOR (2011): Ley Orgánica de la Economía Popular y Solidaria y del Sector Financiero Popular y Solidario, Registro Oficial 444.

REPÚBLICA DEL ECUADOR (2008): Constitución de la República del Ecuador, Registro Oficial 449.

SARRIA, A. \& TIRIBA, L. (2004): "Economía Popular". En: A. Cattani (Org.), La otra economía, Buenos Aires: Altamira, 137-186.

YÉPEZ, P. (2012): Historia de la comunidad "Runa Kawsay": un pueblo indígena urbano en Quito (Tesis de maestría), Flacso-Ecuador, Quito.

YÉPEZ, P. (2014): Kitu Villa Ukupi Runakunapak Kawsaymanta. La vida de los indígenas en la ciudad de Quito, Quito: Flacso-Ecuador. 


\section{Documentos}

Informe final de la consultoría para la factibilidad, anteproyecto y metodología del diseño arquitectónico participativo para la refuncionalización del mercado San Roque-centro histórico de Quito. Fundación Museos de la Ciudad de Quito. Recuperado de www.goo.gl/hhqzDy.
Entrevistas
E: F. C., 2016
E: J. C., 2016
E: P. CH., 2016
E: G. G., 2016
E: G. GU., 2016
E: J. Y., 2016 
